\title{
Design, construction, and implementation of a remote fuel-level monitoring system
}

\author{
Gbenga Daniel Obikoya
}

\begin{abstract}
This research describes a complete fuel-level monitoring system. The research started with the design and construction of a fuel-level sensor and then was followed by configuration of a remote Aplicom 12 GSM module in order to interface the connected sensor. After the module configuration, monitoring of remote fuel is possible by sending control messages from a compatible mobile phone in order to query the status of the remote fuel sensor (and hence the volume of fuel in the tank). The status message from the module will be sent back via a Global System for Mobile Communications (GSM) network to the mobile phone that sent the query (or control) message.
\end{abstract}

Keywords: Sensor; Fuel-level; Status message; Control message

\section{Introduction}

Equipment, such as cars, motorcycles, trucks, generators, and compressors, which is powered by internal combustion engine needs a means of refueling so that it can run for as long and efficiently as possible. The problems associated with this equipment are to know how to contain fuel, to know how much fuel is left, and to know how best the fuel should be stored for users' safety, security, and benefits [1].

In the last few years, escalating oil demands and costs are increasing the cost of many businesses, particularly those with large vehicle fleets, adding to financial burdens in the process of searching for fuel efficiencies [2,3]. For instance, since 2003, fuel prices have doubled in Canada and nearly tripled in USA with consumptions (or demands) continuing to rise, and are never expected to return to 2003 levels [4]. In addition to increasing cost of fuel, there are also cases of fuel theft (from both stationary tank and transport tankers), fuel leakage, premature dry-out, inaccurate fuel refilling, improper engine consumption, and drivers' misbehaviours $[5,6]$. In order to cater the aforementioned problems and avoid damage to reputation, the Aplicom 12 GSM module is used over a Global System for Mobile Communications (GSM) network to provide a practical and cost-effective remote fuel-level monitoring system.

Correspondence: gbenga.obikoya@fuoye.edu.ng

Department of Electrical and Electronics Engineering, Federal University Oye-Ekiti, Oye-Ekiti, Ekiti State, Nigeria

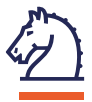

Reza et al. [7] worked on microcontroller-based automated water level sensing and controlling. A microcontroller receives input from the sensor unit which senses the water level via an inverter. After the input variable was processed by the microcontroller, the resultant output (ON/OFF) that represents the water status of the tank was generated. The limitation of this paper is that the system was only implemented locally [7]. Remote monitoring and controlling were later carried out by different authors.

Hemnandan et al. [8] designed and implemented an embedded control-based system for remotely monitoring fuel level of a diesel generator set. When the fuel level status was required, short message service (SMS) was sent to the M33 GSM module in a remote location, and the ultrasonic sensor sensed the fuel status which is then displayed on both LCD display and LED bar graph. Then, alarm was sent back, via a GSM network, to the module. Also, the module was notified when there was fatal error in the system or fuel went down below the minimum required level [8].

Aher and Kokate [2] implemented a microprocessorbased fuel monitoring and vehicle tracking system. This system was placed inside a vehicle to sense the fuel level at various instances with the aid of a reed switch and also tracks the vehicle at various locations with the aid of a GPS device. The data was then read at a central server by using the RS232 protocol. This system is believed 


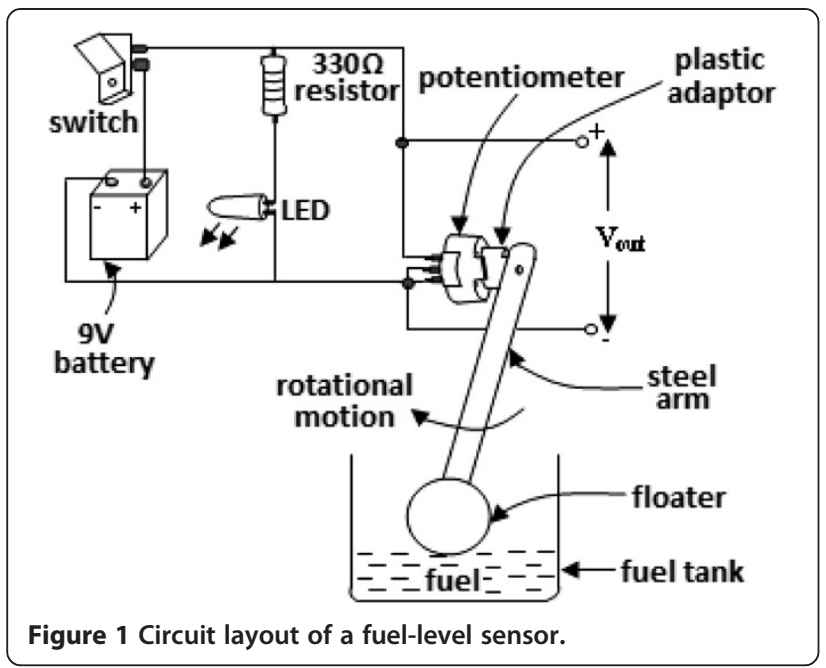

to perform the tasks of detecting fuel theft and tracking the vehicle accurately and continuously [2].

Senthilraja et al. [9] worked on detection of fuel theft and vehicle position with a third party monitoring software. The overall system consists of an ultrasonic fuel sensor, numeric lock (for authentication/security purpose), and third party monitoring software (for providing notifications about fuel theft). Whenever, fuel is being stolen, the sensor will store the information in the database and from where it provides the notification based upon calculations by the third party monitoring software. This system has provided periodic details about fuel level and vehicle position, and this will help to eliminate fuel theft and vehicle theft problems [9].

The current research starts from the design and the construction of a remote fuel-level sensor and then is followed by remote monitoring of the fuel level in the remote tank. Monitoring is possible by sending control messages from a compatible mobile phone in order to query the status of the remote sensor (placed on a remote tank). This fuel-level monitoring system will ensure efficient use of fuel, minimize operating cost, and help realize maximum profit.

\section{Design and construction}

\subsection{Design}

The circuit layout of the fuel-level sensor is shown in Figure 1.

The fuel-level sensor was properly placed on a fuel tank with total volume of $27 \mathrm{~cm} \times 27 \mathrm{~cm} \times 37.5 \mathrm{~cm}$. This is shown in Figure 2a. The geometry formed by the sensor arm and floater is shown in Figure 2b.

It is obvious from Figure $2 b$ that

$$
\cos \theta=\frac{Z}{l} \text { or } z=l \cos \theta
$$

where $l$ is the length of the sensor (in $\mathrm{cm}$ ), $z$ is the height of the vacuum existing between the top of the fuel level in the tank and the top of the tank (in $\mathrm{cm}$ ).

Since $l=23 \mathrm{~cm}$, it then implies that

$$
z=23 \cos \theta \quad(\mathrm{cm})
$$

and also

$$
H=z+h \quad \text { or } \quad h=H-z
$$

where $h$ is the height of the fuel in the tank.

Substituting Equation 2 into Equation 3 and knowing well that $H=37.5 \mathrm{~cm}$, Equation 4 is then established.

$$
h=37.5-23 \cos \theta \quad(\mathrm{cm})
$$

Volume $V$ of the fuel in the tank is given by

$$
V=h \times A
$$

where $A$ is the area of the tank.
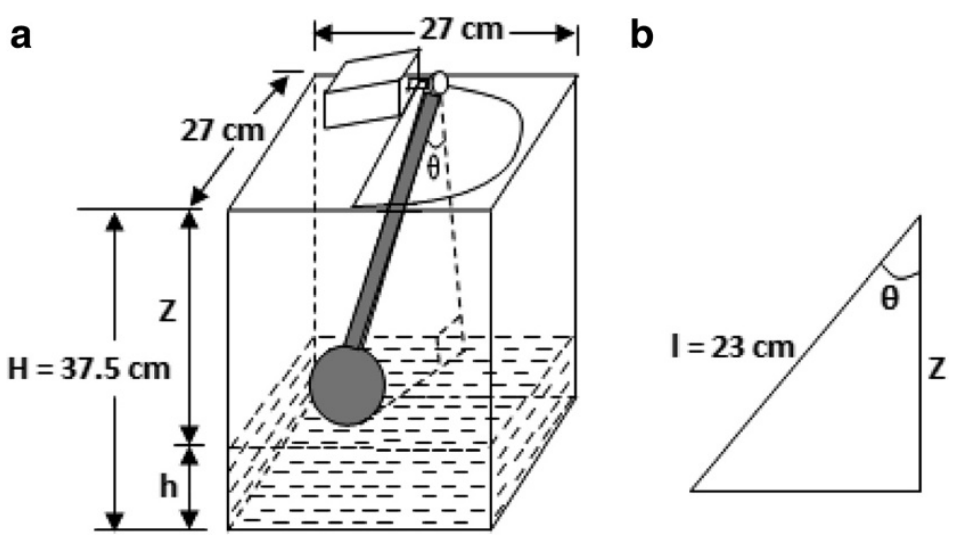

Figure 2 Fuel-level sensor design diagram. (a) Fuel-level sensor mounted on the fuel tank. (b) Geometry formed by the sensor arm and floater. 
a

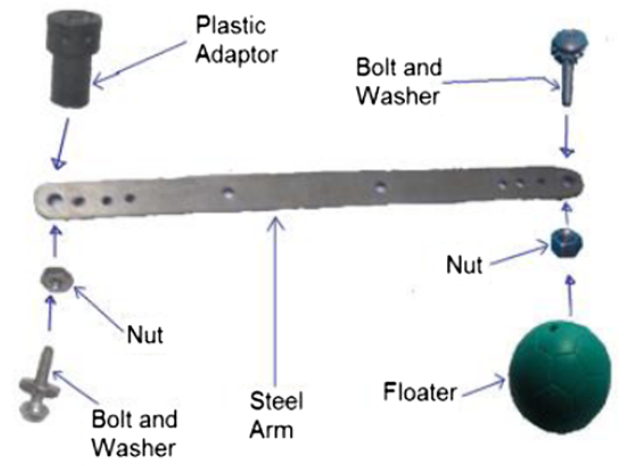

b

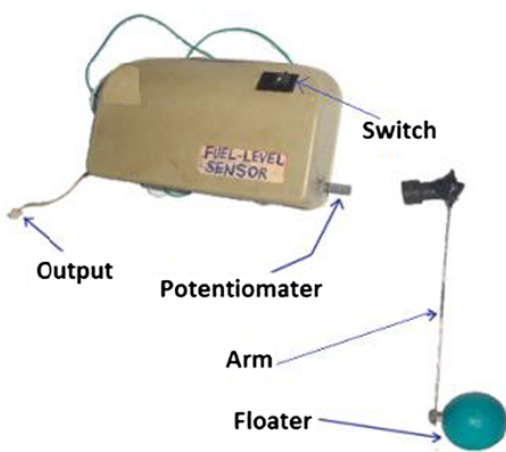

Figure 3 Construction of a fuel-level sensor. (a) Assembly of arm and floater. (b) Assembly of a complete fuel-level sensor.

Substituting Equation 4 into Equation 5 and knowing that area $A=27 \mathrm{~cm} \times 27 \mathrm{~cm}$, Equation 6 below is achieved.

$$
\begin{aligned}
& V=(37.5-23 \cos \theta) \mathrm{cm} \times 27 \mathrm{~cm} \times 27 \mathrm{~cm} \\
& V=729(37.5-23 \cos \theta)\left(\mathrm{cm}^{3}\right)
\end{aligned}
$$

Since $1,000 \mathrm{~cm}^{3}=1 \mathrm{~L}, V$ therefore becomes

$$
\begin{aligned}
& V=\frac{729}{1,000}(37.5-23 \cos \theta) \\
& \therefore V=27.3375-16.767 \cos \theta \quad \text { (liters) }
\end{aligned}
$$

The potentiometer equation states that

$$
V_{\text {out }}=V_{\text {in }} \times \frac{\theta}{\theta_{\mathrm{T}}}
$$

where $\theta$ is the angle of rotation of the potentiometer, $\theta_{\mathrm{T}}$ is the total angle through which the potentiometer can rotate $\left(280^{\circ}\right), V_{\text {in }}$ is the input voltage from a direct current $(\mathrm{DC})$ source $(9 \mathrm{~V}=9,000 \mathrm{mV})$.

$$
V_{\text {out }}=\frac{9,000 \theta}{280} \text { or } \frac{225 \theta}{7} \text { (volts) }
$$

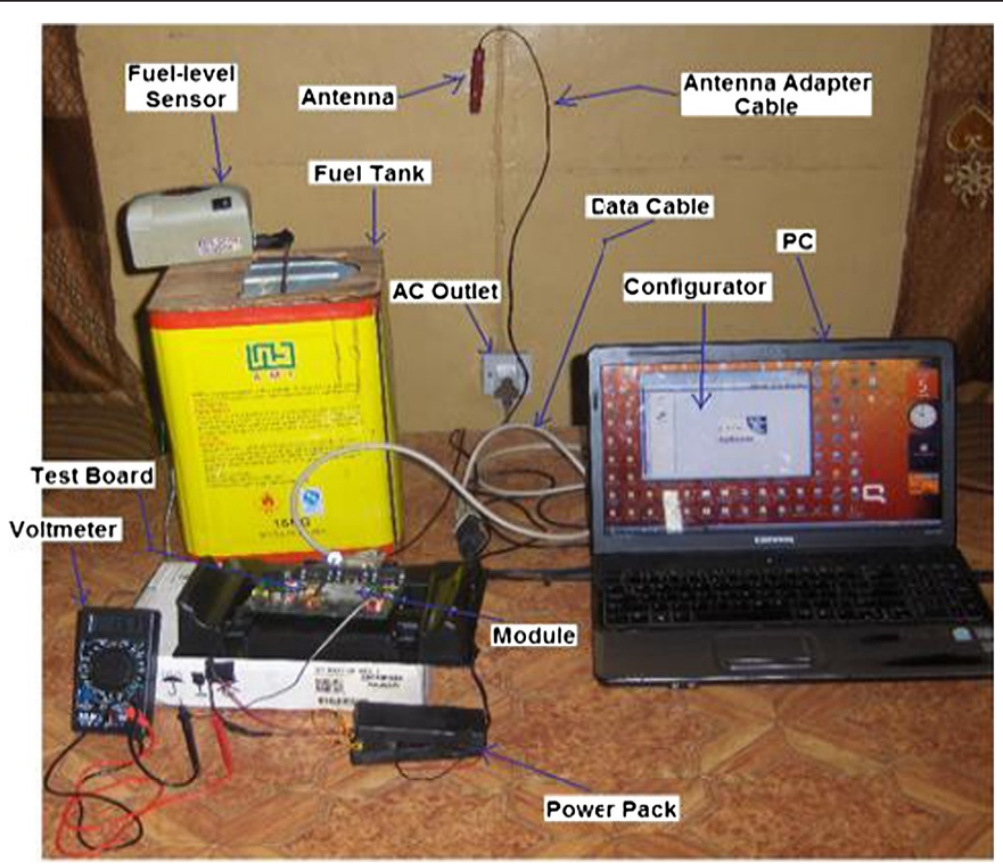

Figure 4 Research experimental setup. 


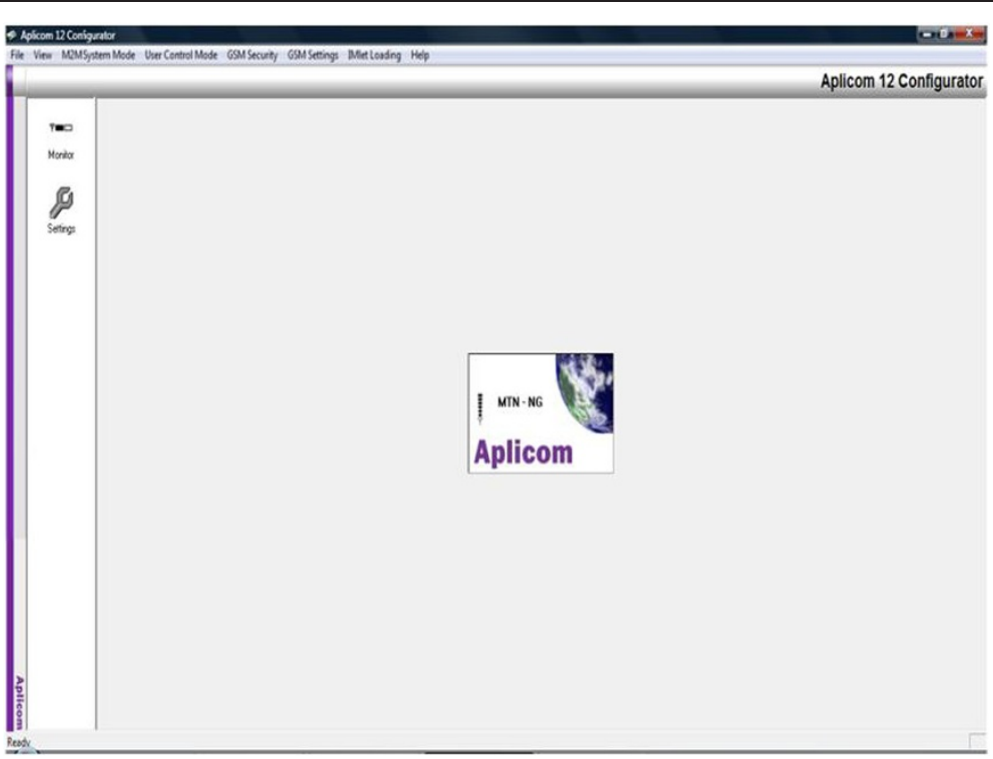

Figure 5 Configurator start-up dialog.

It is established from Equation 4 that

$$
\theta=\cos ^{-1}\left(\frac{37.5-h}{23}\right)
$$

By putting Equation 12 in Equation 11, Equation 13 below is established.

$$
V_{\text {out }}=\frac{225}{7} \cos ^{-1}\left(\frac{37.5-h}{23}\right) \quad(\text { volts })
$$

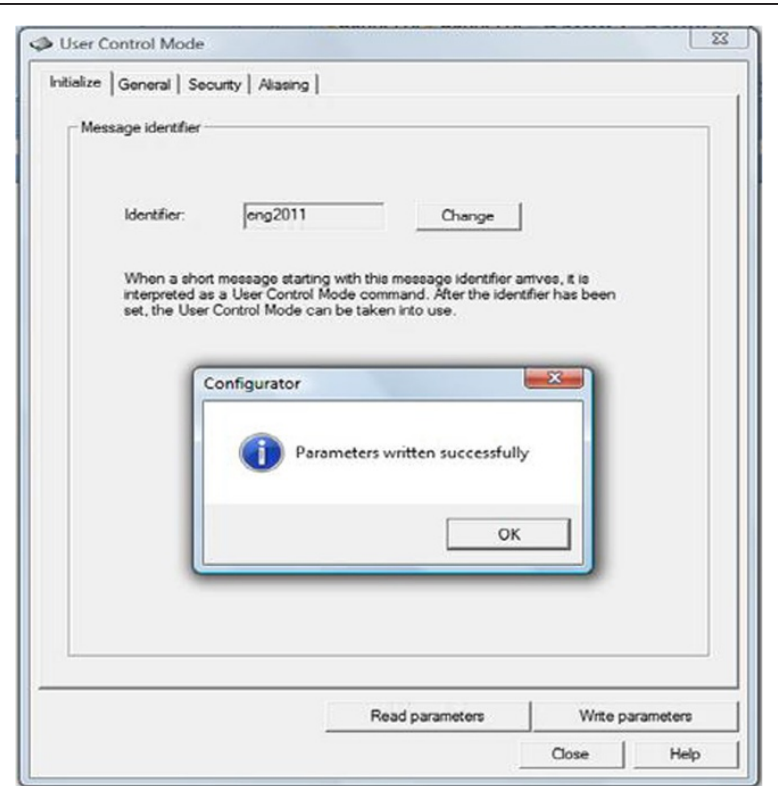

Figure 6 Dialog for setting message identifier.
The height $h$ of the fuel in the tank can also be calculated in terms of output voltage by making $\theta$ in Equation 11 the subject of the formula, i.e.,

$$
\theta=\frac{7}{225} V_{\text {out }}
$$

Putting Equation 14 into Equation 4, Equation 15 is derived.

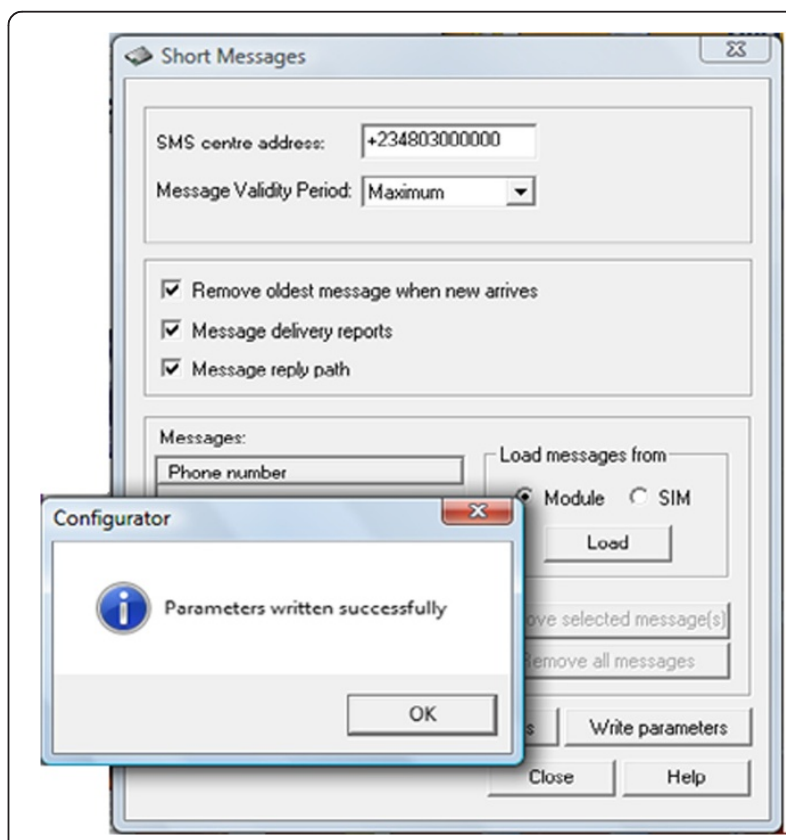

Figure 7 Dialog for setting the message center and the short messages. 


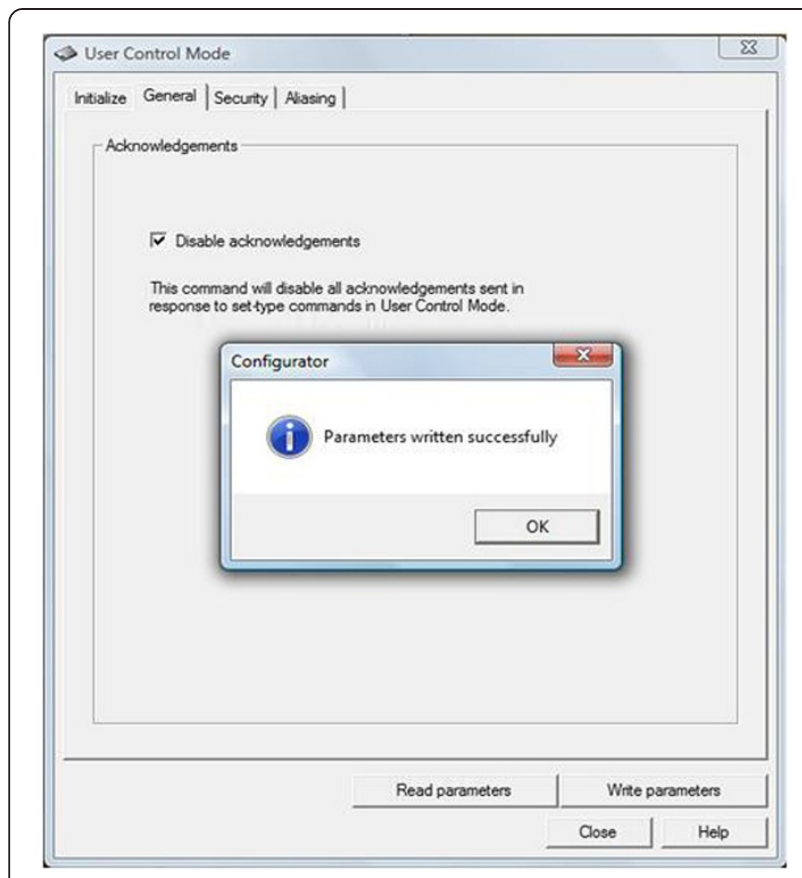

Figure 8 Dialog for disabling acknowledgement.

$$
h=37.5-23 \cos \left(\frac{7}{225} V_{\text {out }}\right) \quad(\mathrm{cm})
$$

Therefore, the fuel volume at a given output voltage can be derived by putting Equation 15 into Equation 5 . Equation 16 is therefore obtained.

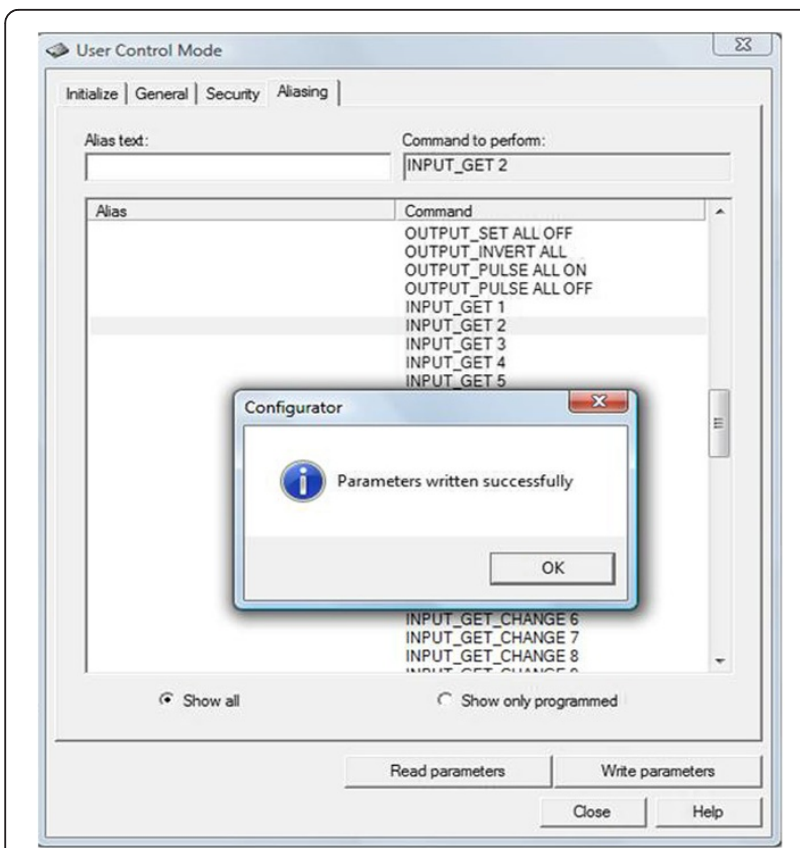

Figure 9 Dialog for setting aliasing for device commands.

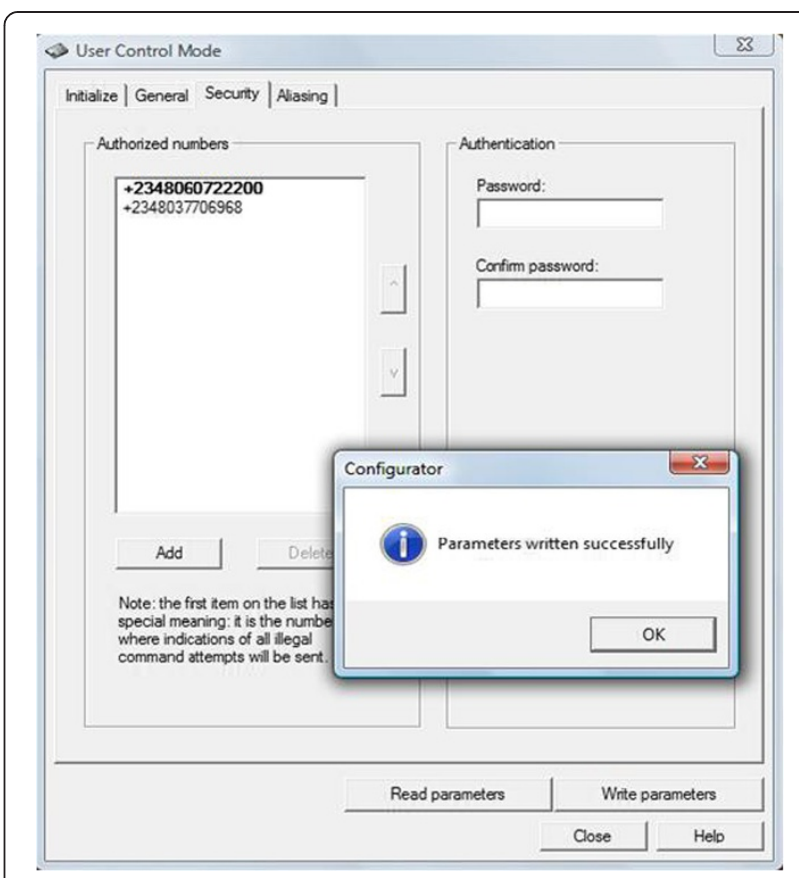

Figure 10 Dialog for security setting.

$$
V=A\left[37.5-23 \cos \left(\frac{7}{225} V_{\text {out }}\right)\right]
$$

Since the tank has a constant area $A$ of $27 \mathrm{~cm} \times 27 \mathrm{~cm}$, Equation 17 below is established.

$$
V=0.729\left[37.5-23 \cos \left(\frac{7}{225} V_{\text {out }}\right)\right] \quad \text { (liters) }
$$

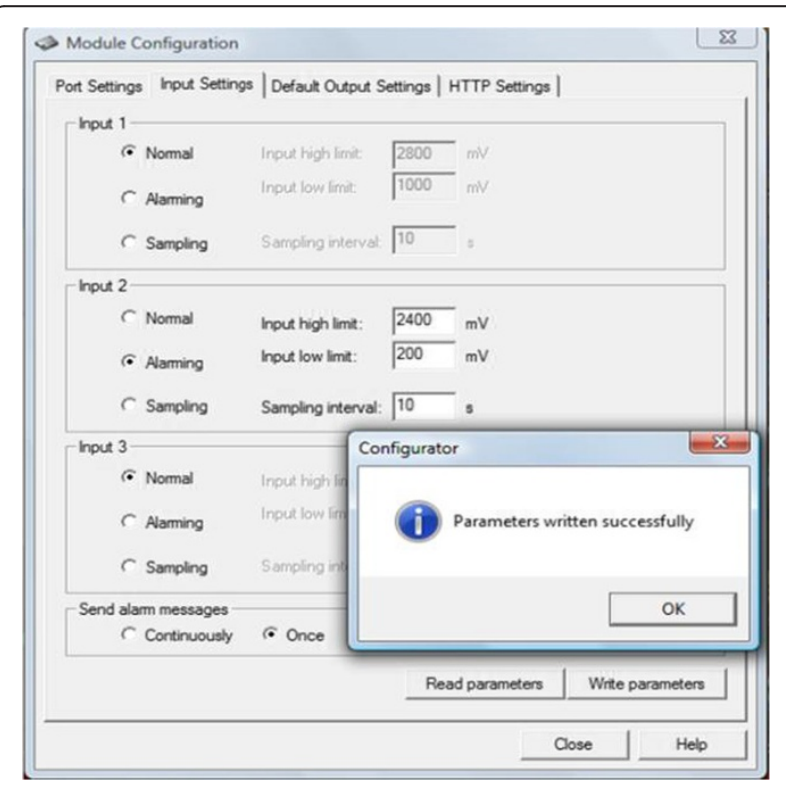

Figure 11 Dialog for setting input limits. 


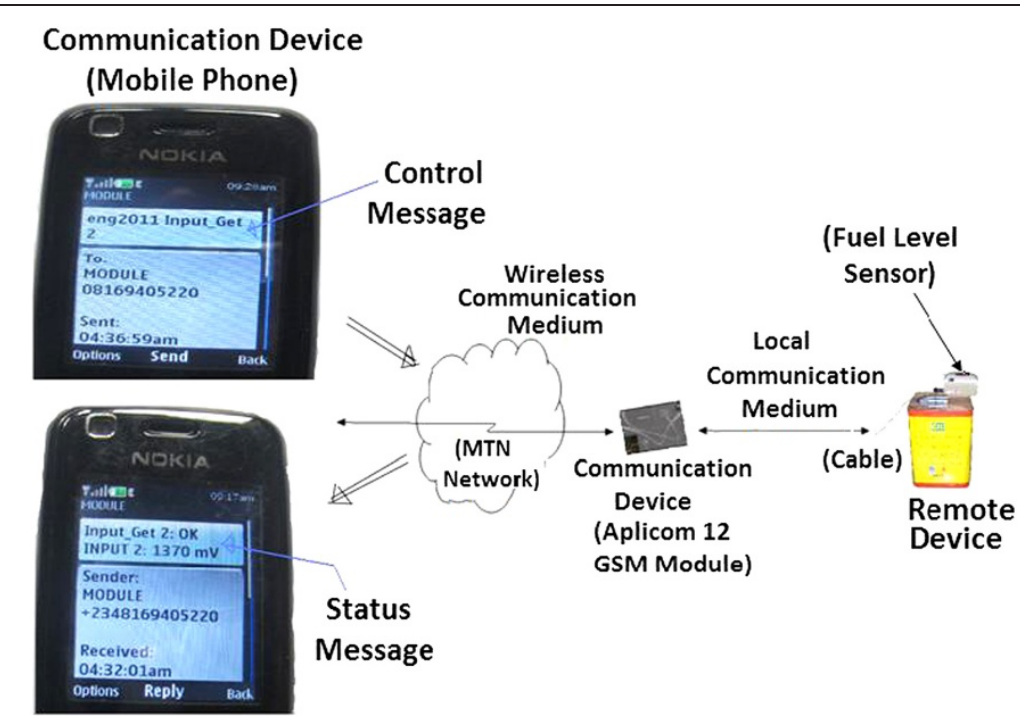

Figure 12 Remote fuel-level monitoring system.

\subsection{Construction of a fuel-level sensor}

Construction of the sensor was carried out with materials such as a rotary potentiometer (or variable resistor), 9-V battery, switch, LED, resistor, floater, steel arm, plastic adaptor, screws, wire, and fuel tank. The arm and floater assembly was constructed by mounting the floater with a bolt and nut to an accurately dimensioned steel arm. A plastic adaptor was then attached on this assembly as shown in Figure 3a. The sensor circuit was properly placed in a suitable casing. With the potentiometer extending out of the casing, an assembly of arm and floater was mounted on the potentiometer with the aid of the plastic adaptor as shown in Figure 3b.

After the whole construction, the workability of the fuel sensor was confirmed. This was done by mounting the fuel sensor on the fuel tank, and as the fuel level in

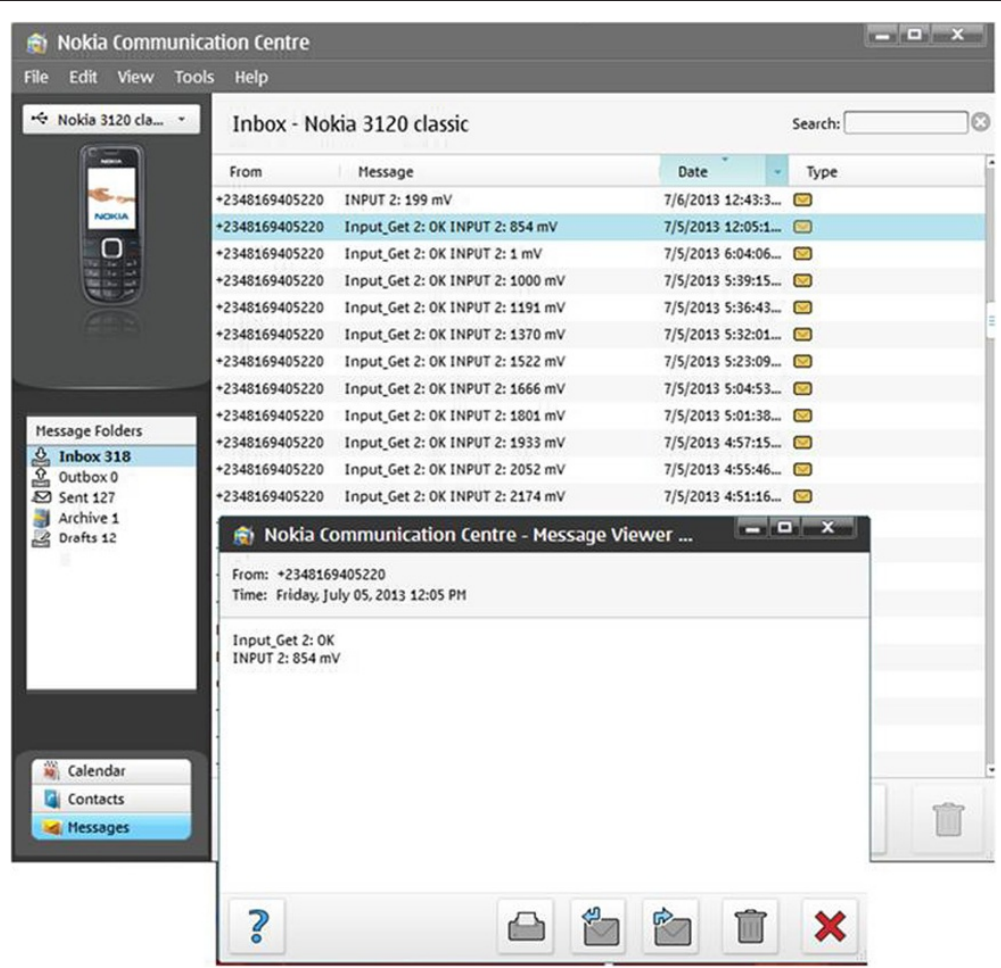

Figure 13 Message dialog for monitoring fuel level of remote tank. 


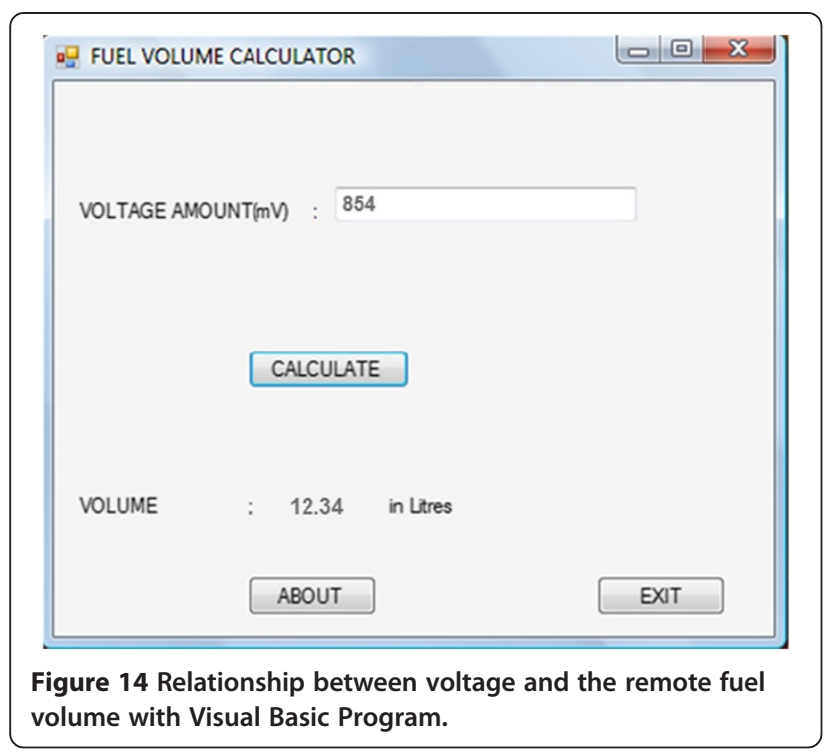

Figure 14 Relationship between volta
volume wisual Basic Program. the tank increased, the floater began to rise up, thereby rotating the potentiometer. The voltmeter was used to verify the expected increase in voltage.

\section{Implementation}

The research experiment was set up using the constructed fuel-level sensor, fuel tank, Aplicom 12 GSM module, Aplicom 12 test board, power supply, PC, data cable, jumper connector, antenna, antenna adapter cable, mobile phone, and mobile telephone number (MTN) SIM card. The following experimental steps were taken [10]:

- The GSM module was mounted to the 60-pin connector on the test board.

- An MTN SIM card was inserted into the SIM card holder on the test board.

- The antenna was connected to the module with the antenna adapter cable.

- The PC with already installed configurator software was connected to a D9 com port 2 on the test board through a data cable AXS-3.

- Communication mode switch on the test board was turned ON to normal, and RS-232 switch was also turned $\mathrm{ON}$.

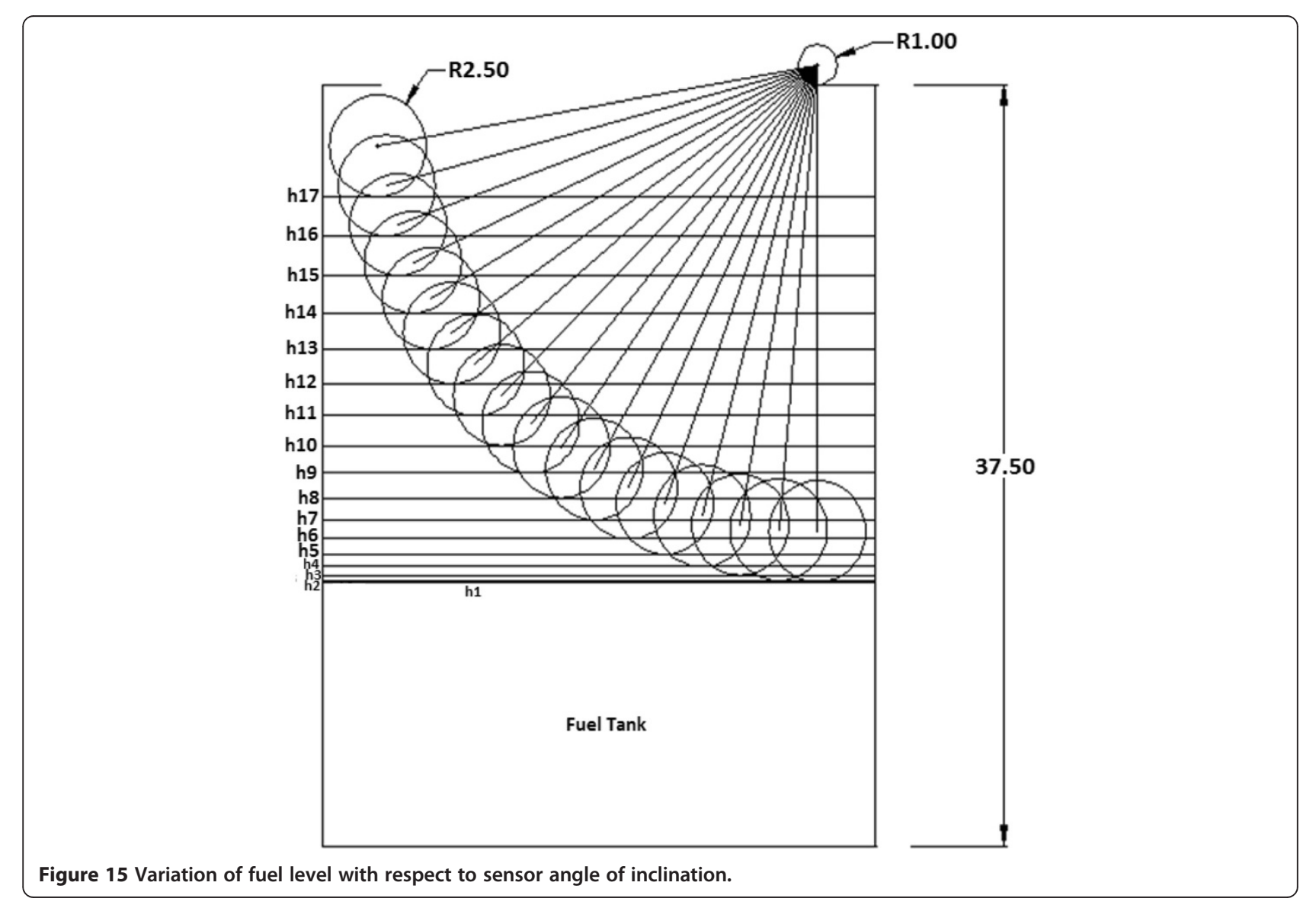


- The fuel-level sensor (which was mounted on the fuel tank) was connected to pin header 2 on the test board through a jumper connector.

- DC power supply was connected to the test board and then to an AC wall outlet.

The picture illustrating the above steps is shown in Figure 4.

After the completion of the experimental setup, the installed configurator was opened on the PC. M2M system protocol in the preference dialog box (File- > Preferences) was selected as the communication type, and the dialog in Figure 5 appeared on the PC [11].

After the connection was established between the module and the PC as shown in Figure 5, the following configuration steps were effected before control messages could control the module:

- Message identifier was set using the dialog box (User Control Mode- > Settings- > Initialize) as shown in

Figure 6. The message identifier was set with the string 'eng2011' and then 'change' was clicked and lastly

'Write parameter' to activate the new identifier $[6,10,12]$.

- SMS center address was set using the dialog box (GSM Settings- > Advanced- > Short Messages) as shown in Figure 7. 'Read parameters' button was pressed, and it was verified that the MTN SMS center address +2348030000000 was available. 'Remove oldest messages when new arrives' option was selected so that the oldest message would be removed from the SIM card and the module when a new message arrives. This allowed the control messages to get to their destination, thereby fulfilling their control purposes. Lastly, the parameters were written by clicking the 'Write parameter' button $[6,10,12]$.

- Acknowledgement was disabled during the experiment to limit the amount of communication with the module, consequently reducing the cost of sending text messages over the MTN network. This was effected using the dialog box (User Control Mode- > Settings- > General) as shown in Figure 8. The parameter was therefore written using the "Write parameter' button $[6,10,12]$.

- Aliasing was defined in the dialog box (User Control Mode- > Setting- > Aliasing) as shown in Figure 9. Aliasing was defined using INPUT_GET 2, and this automatically replaces the default command. The parameters were therefore written by clicking on the 'Write parameter' button $[6,10,12]$.

- Authorized numbers were entered into the module in the dialog box (User Control Mode- > Settings- > Security) as shown in Figure 10. This was done to avoid misuse of the module and only restrict the authorized number to know the status of the fuel level. The first number in bold notified of an unauthorized control attempt. 'Write

Table 1 Relationship between sensor inclined angles, corresponding heights of fuel, different volumes of fuel, and output voltages

\begin{tabular}{|c|c|c|c|c|c|c|}
\hline \multirow{2}{*}{$\begin{array}{l}\text { Angle } \\
\text { (degree) }\end{array}$} & \multicolumn{2}{|c|}{ Height (cm) } & \multicolumn{2}{|c|}{ Volume (liters) } & \multicolumn{2}{|c|}{ Output voltage (volts) } \\
\hline & $\begin{array}{l}\text { Measured } \\
\text { (geometry) }\end{array}$ & $\begin{array}{c}\text { Calculated } \\
h=37.5-23 \cos \theta\end{array}$ & $\begin{array}{l}\text { Measured (geometry) } \\
\qquad V=A \times h\end{array}$ & $\begin{array}{c}\text { Calculated } \\
V=0.729(37.5-23 \cos \theta)\end{array}$ & $\begin{array}{l}\text { Measured } \\
\text { (geometry) }\end{array}$ & $\begin{array}{c}\text { Calculated } \\
V_{\text {out }}=\frac{9}{280} \cos ^{-1}\left(\frac{37.5-h}{23}\right)\end{array}$ \\
\hline 0 & 14.50 & 14.50 & 10.57 & 10.57 & 0.00 & 0.000 \\
\hline 5 & 14.60 & 14.59 & 10.64 & 10.63 & 0.16 & 0.163 \\
\hline 10 & 14.85 & 14.85 & 10.83 & 10.83 & 0.32 & 0.322 \\
\hline 15 & 15.30 & 15.28 & 11.15 & 11.14 & 0.48 & 0.481 \\
\hline 20 & 15.90 & 15.89 & 11.59 & 11.58 & 0.64 & 0.644 \\
\hline 25 & 16.65 & 16.65 & 12.14 & 12.14 & 0.80 & 0.803 \\
\hline 30 & 17.60 & 17.58 & 12.83 & 12.82 & 0.96 & 0.964 \\
\hline 35 & 18.65 & 18.66 & 13.60 & 13.60 & 1.13 & 1.125 \\
\hline 40 & 19.85 & 19.88 & 14.47 & 14.49 & 1.29 & 1.286 \\
\hline 45 & 21.25 & 21.24 & 15.49 & 15.48 & 1.45 & 1.447 \\
\hline 50 & 22.70 & 22.72 & 16.55 & 16.56 & 1.61 & 1.608 \\
\hline 55 & 24.30 & 24.31 & 17.71 & 17.72 & 1.77 & 1.768 \\
\hline 60 & 26.00 & 26.00 & 18.95 & 18.95 & 1.93 & 1.929 \\
\hline 65 & 27.80 & 27.78 & 20.27 & 20.25 & 2.09 & 2.089 \\
\hline 70 & 29.65 & 29.63 & 21.61 & 21.60 & 2.25 & 2.250 \\
\hline 75 & 31.65 & 31.55 & 23.00 & 23.00 & 2.41 & 2.411 \\
\hline 80 & 33.50 & 33.51 & 24.42 & 24.43 & 2.57 & 2.572 \\
\hline
\end{tabular}


Table 2 Comparison between the received volume and the measured volume

\begin{tabular}{ll}
\hline Volume (liters) [measured] & $\begin{array}{l}\text { Volumes (liters) [Received } \\
\text { from the module] } \\
\boldsymbol{V}=\mathbf{0 . 7 2 9}\left[\mathbf{3 7 . 5}-\mathbf{2 3} \cos \left(\frac{\mathbf{2 8 0}}{\mathbf{9}} \boldsymbol{V}_{\text {out }}\right)\right]\end{array}$ \\
\hline 24 & 23.96 \\
23 & 22.90 \\
22 & 21.99 \\
21 & 20.96 \\
20 & 19.95 \\
19 & 18.99 \\
18 & 17.97 \\
17 & 16.98 \\
16 & 15.98 \\
15 & 15.00 \\
14 & 13.96 \\
13 & 12.98 \\
12 & 11.99 \\
11 & 10.98 \\
\hline
\end{tabular}

parameter' was then clicked to activate the authorized numbers $[6,10,12]$.

- Analog inputs were set in the dialog box (File- > Module Configuration- > Input Settings) as shown in Figure 11. A high limit of 2,400 $\mathrm{mV}$ and low limit of $200 \mathrm{mV}$ were set to analog input pin 2, such that alarm messages were sent to the originating mobile phone when limits were crossed. 'Once' option was selected to reduce the amount of alarms sent over an MTN network, consequently reducing the cost of transferring excess text messages. Lastly, parameters were written by clicking on the 'Write parameter' button $[6,10,12]$.

\section{Monitoring}

In general, a remote fuel-level monitoring system consists of four major components which are communication devices, remote device (fuel-level sensor in this case), messages (both control and status messages), and communication media [3].

After completing the module configuration, control messages were sent from a compatible mobile phone, over an MTN network, to the module for monitoring the different volumes of fuel in the remote tank. The control messages were sent by adding the message identifier 'eng2011'. The responses were instantly sent back to the mobile phone which sent the queries as shown in Figure 12.

The mobile phone in Figure 12 was connected to a computer system via a USB cable in order to ensure further monitoring of the remote tank. The message window on the PC is shown in Figure 13.

Equation 17 was programmed into Visual Basic which was then installed on a computer system in order to easily and quickly determine the volume of fuel as soon as the voltage level is received from the remote tank. An instance of voltage received, i.e., $854 \mathrm{mV}$, is used to compute the required volume as shown in Figure 14.

\section{Results}

When the volume (and the corresponding height) was increased in the fuel tank, the angle of inclination of the sensor, with respect to the fuel tank, increases. This fact was further confirmed by the diagram in Figure 15.

The height, volumes, and output voltage were measured using the geometrical method as in Figure 15, and the results were compared with the experimental value as shown in Table 1.

Also, after various voltage levels were received from the GSM module, fuel volumes were computed with the

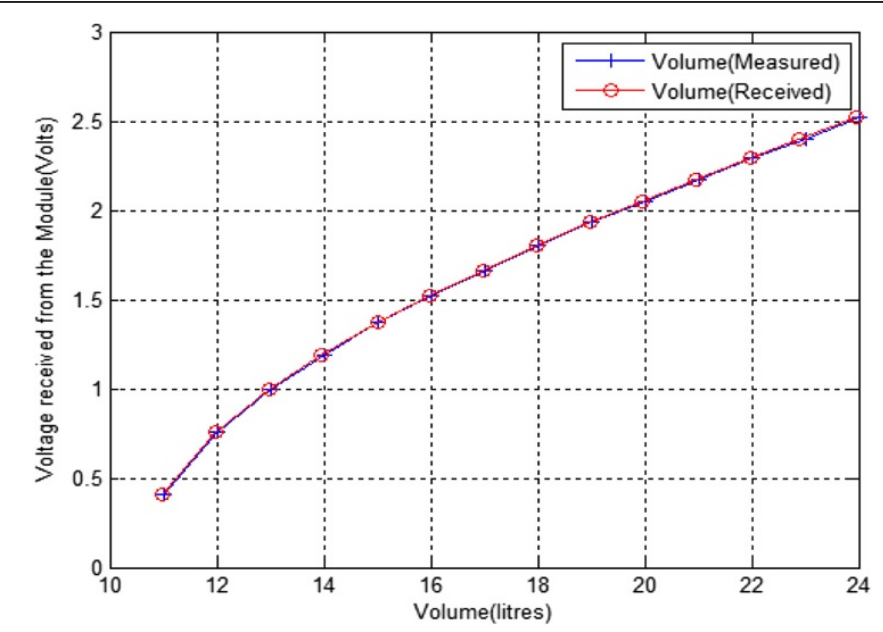

Figure 16 Plot of output voltage received from remote Aplicom 12 GSM module against fuel volumes (measured and received). 
Visual Basic Program, and the results were compared with the measured volume derived from the geometrical method. This is shown in Table 2.

The plot of voltage levels received from the GSM module is plotted against the calculated values using Table 2. The resulting plot is shown in Figure 16.

\section{Conclusion}

It is seen from this research that whenever an authorized mobile phone sent a message to query the status of the fuel in the remote tank, a voltage level (which is approximately equal to the value of the measured voltage) will be received by the mobile phone from which the query was sent. Also, the volume results from the Visual Basic Program are approximately the same as the measured volume values.

Therefore, the type of monitoring system implemented in this research is seen to be accurate and reliable, and this will surely provide a solution to the challenges faced in monitoring the fuel level of both stationary tanks and mobile tanks. The problems due to rising cost of fuel, theft, mismanagement, delay, losses, and damage to reputation will be immensely reduced (if not even eliminated). This system will consequently minimize operating cost and maximize profit for individuals, governments, and businesses with large vehicle fleets.

\section{Competing interests}

The author declares that he has no competing interests.

\section{Acknowledgements}

The author is thankful to Tertiary Education Trust Fund (TETFund) for the sponsorship of this publication.

Received: 2 January 2014 Accepted: 26 March 2014

Published: 14 May 2014

\section{References}

1. S Jaslyn, Fuel level sender - the inside story. Ezine Articles, 2010, http://ezinearticles.com/?Fuel-Level-Senders-The-inside-story\&id=4580730. Accessed 20 January 2011

2. SS Aher, RD Kokate, Fuel monitoring and vehicle tracking. Int. J. Eng. Innovat. Technol. 1(3), 166-169 (2012)

3. SkyWave Mobile Communication, Remote fuel-level monitoring. Application Note, 2010, pp. 1-3, http://www.skywave.com/content/whitepapers/ skywave_fuellevel_application_note_eng.pdf. Accessed 21 March 2012

4. A Sood, Fuel optimization using on-board diagnostic information. SkyWave Mobile Communication, 2008, p. 1, 3-5, 9-10, http://www.skywavemobile. com/en/products/data-network-services/184-fuel-optimization-whitepaper. pdf. Accessed 21 January 2011

5. Solid Applied Technology Ltd, Fuel theft prevention and fuel level monitoring, 2010, http://www.solidat.com/content.asp?id=772. Accessed 31 February 2010

6. GD Obikoya, D Ogungbaigbe, OA Okenu, Monitoring and controlling fuel level of remote tanks using Aplicom 12 GSM module. ARPN J. Eng. Appl. Sci. 6(1), 56-60 (2011)

7. SM Khaled Reza, SA Md Teriq, SM Mohsin Reza, Microcontroller based automated water level sensing and controlling: design and implementation issue, in Proceeding of the World Congress on Engineering and Computer Science, vol. 1 (San Francisco, USA, 2010), pp. 1-5

8. GM Hemnandan, G Gajanan, R Anil, Remote monitoring of fuel level for diesel generator set, in National Conference on Electronic Technologies (Ponda-Goa, India, 2011), pp. 1-3
9. P Senthilraja, C Rukumani Khandhan, M Padaniappan, J Vinumathi, L Rama, P Sai Sushimitha, R Madhan, Detection of fuel theft and vehicle position with third party monitoring software. Int. J. Adv. Computational Eng. Networking 1(7), 37-39 (2013)

10. Aplicom, Aplicom 12 GSM Module Remote I/O Control Guide, 2005, pp. 1-34 http://www.aplicom.com/...k/502875_a12_properties_reference_guide.pdf. Accessed 6 February 2010

11. Aplicom, Aplicom 12 Configurator Software, 2005, http://www. configureOne.co.uk/Configurator. Accessed 31 February 2010

12. Aplicom, Aplicom 12 GSM Module User Control Mode Guide, 2005, pp. 2-29, http://www.aplicom.com/...k/502875_a12_properties_reference_quide.pdf. Accessed 29 January 2010

doi:10.1186/1687-1499-2014-76

Cite this article as: Obikoya: Design, construction, and implementation of a remote fuel-level monitoring system. EURASIP Journal on Wireless Communications and Networking 2014 2014:76.

\section{Submit your manuscript to a SpringerOpen ${ }^{\circ}$ journal and benefit from:}

- Convenient online submission

- Rigorous peer review

- Immediate publication on acceptance

- Open access: articles freely available online

- High visibility within the field

- Retaining the copyright to your article

Submit your next manuscript at $>$ springeropen.com 